\title{
Do transparent government agencies strengthen trust?
}

\author{
Stephan Grimmelikhuijsen \\ Utrecht School of Governance (Utrecht University), Bijlhouwerstraat 6, 3511 ZC Utrecht, The \\ Netherlands
}

\begin{abstract}
Trust in government has been shown to be volatile in recent years and Internet transparency is seen as a solution to strengthen trust. However, critics argue that transparency will only lead to less trust, and sceptics say that it has no effect at all. This debate on transparency is lacking empirical information, and therefore central to this article is to what extent transparency influences trust. Three dimensions of trust are distinguished: the competence, benevolence and honesty of the government agency in question. To examine whether Internet transparency affects these dimensions, an experimental design was used which compared results from three groups of volunteers. The groups were given varying amounts of prior information regarding the government agency, ranging from much to none. Results showed that the relationship between Internet transparency and these dimensions of trust is not unequivocal. Perceptions of benevolence and honesty are affected by the level of transparency, while perceptions of competence remain stable. Hence, a heterogeneous effect of transparency on trust is demonstrated. This calls for a more refined view in the debate on this relationship; this study offers a beginning point for more detailed insight in the various effects of transparency on trust.
\end{abstract}

Keywords: Trust, electronic government, government websites, Internet, policy information

\section{Introduction}

Trust in government has been shown to be volatile in recent years. Several authors have stressed a steady decline in trust in a variety of countries (e.g. [39]). Although the level of trust in government has recovered somewhat in recent years [9], transparency is seen as a solution to strengthen trust [10,40]. However, some critics argue that increased transparency will only lead to less trust [38], while others believe that it will have no effect at all [7].

Transparency is seen by policy makers and some scholars as a panacea for enabling 'good governance' [23,24]: it is said to be something that is best for all. It makes government officials perform better and it prevents corruption [34]. The call for a more transparent government fits within a politicoadministrative development towards a more accessible public administration sector. This could enhance citizens' trust in government [4]. Parallel to this, the use of the Internet possibly contributes to increased government transparency. Huge amounts of information can be released at a relatively low cost. This information can be read by anyone with access to the Internet; independent of time or place. It is said that the "Internet enables transparency" [13,22, p. 5]. The Internet revolution has created an information culture in which citizens have - and expect - access to a great deal of information [42].

\footnotetext{
${ }^{*}$ Corresponding author: Stephan Grimmelikhuijsen MSc, Utrecht School of Governance (Utrecht University), Bijlhouwerstraat 6, 3511 ZC Utrecht, The Netherlands. Tel.: +30 2531433; Fax: +30 2537200; E-mail: s.g.grimmelikhuijsen@uu.nl.
} 
Trust in government and its agencies is regarded as an essential element in developed societies; if institutions are not trusted by the citizens they serve, they cannot function. Many scholars argue that if government is perceived as being trustworthy, then citizens tend to comply more often with the demands, laws and regulations of government $[1,29]$. Also, a trustworthy government generates interpersonal trust among citizens, allowing the economy to run smoothly and maintaining the country's prosperity [19, $25,29,41]$. Giddens [21,34] emphasizes the importance of trust mechanisms to make complex societies work; the significance of open government in generating trust has grown immensely.

In short, trust in government is said to be declining among citizens; the call for transparency is aimed at restoring this [43]. But does transparency really contribute to higher levels of citizen trust? For instance, Bouckaert and Van de Walle [7] argue that there might be no relationship between trust and what government is or does. According to them, trust in government is rooted in a general disposition to trust, rather than that it is influenced by actual government performance. This would mean that transparency has no effect at all on citizen trust. On the other hand, scholars argue that transparency could even lower current trust levels, because it makes it possible to (unduly) criticize government on more and more specific points [8]. Further, O'Neill contends that transparency could lead to an information overload, confusion and thus uncertainty. In this way we could get lost in misinformation which will produce less trust, leading to the rise of a "culture of suspicion" [38, p. 77]. This debate on transparency and trust is mainly theoretical. To date there is no strong empirical proof for any of these positions; there is a shortage of empirical information about whether transparency through the Internet in fact influences citizen trust in government [43]. From the debate outlined above, the following question arises, which is the central issue of this paper.

\section{To what extent does Internet transparency of government have an effect on citizen trust in government agencies?}

This paper seeks to contribute empirically to the debate by using an experiment. Two groups visited the website of a Dutch municipality with information about the air quality policy. One group visited a highly transparent website, that is, with a great deal of information; a second group of participant visited another version of the website which had a low level of transparency, i.e. website with only little information. A third group did not visit the website with information about the air quality policy at all. The group that visited a highly transparent website was compared to the two other groups (i.e. the two control groups). Further, the two control groups with no and a little information were compared with each other. This method is very suitable for assessing the causal effect in a relationship, which is relevant in this study because it is unknown whether transparency causes higher levels of trust.

\section{Citizen trust in government}

Political trust has many denotations attached; one of them is the trust of citizens in government. A great deal of research has been done by employing different perspectives on citizen trust. Also, respondents participating in surveys have different associations to subjects which scholars judge as being the same [15]. To overcome these problems and to limit this study, we will focus on a specific type of citizen trust in government: trust in particular government agencies. This means that this study focuses on a specific part of a governmental organization. This specific focus makes it possible to be much more precise when questioning people about the object of trust. It also enables a more accurate measurement 
of trust, because general trust in government is possibly influenced by other factors which cannot be caught in an experiment (for example, economic tide).

How will trust be examined? From a sociological perspective, trust is an attitude towards an object [12], in this case a government agency. Trust in a government agency is seen as the multidimensional perception of it as held by citizens: whether or not the agency is perceived as being trustworthy. Based on a literature review, trustworthiness consists of three dimensions which are common to most definitions of trust [5, $11,26,27,31-33,36,47]$. Most of these authors found competence, benevolence and honesty to be the most important dimensions of trust. Although some authors recognize additional dimensions such as predictability, or formulate dimensions in a slightly different way, these three dimensions are most common throughout the literature on trust. The dimension of benevolence concerns the level to which participants perceive the government agency as showing genuine care for citizens. Competence describes the extent to which participants perceive that the government agency is sufficiently competent to carry out its tasks. Honesty refers to whether participants believe that the government agency performs its duties soundly, i.e., tells the truth.

\section{Transparency and the Internet}

Transparency is a broad concept; therefore the following broad definition proposed by Birkinshaw [6, pp. 189-191] will be used: "Transparency is the conduct of public affairs in the open or otherwise subject to public scrutiny."

This means transparency of governmental agencies is a horizontal relationship between bureaucracy and citizens, with an inward perspective; the citizen watches the agency from the outside. Also, we focus on informational transparency through the Internet. The Internet is used to disclose information about as well as from government. The Internet as a medium enables the widespread use of transparency by government agencies and citizens [13]. Information is not bound to certain a jurisdiction; when it is disclosed on the Internet it is directly available, without regard to geographical and political boundaries. The Internet is increasingly used for obtaining information from websites of public authorities. Euro barometer data shows that the percentage of Internet users in the European Union who obtained information from public authority websites increased from 41 percent in 2005 to 47 percent in 2007. US survey data shows that government websites are used by 50 percent of all Americans and 75 percent of American Internet users [43].

Two broad interconnected concepts of transparency are debated. First, transparency is seen as a policy instrument of government: by providing information, government facilitates the decision making of citizens [22, p. 20]. Second, transparency is said to be a democratic value. This is part of a broad change from 'government' to 'governance' that came into fashion in the 1980s, with the emergence New Public Management as one of the main principles of the good governance doctrine [28]. This view that transparency is an essential element for a highly performing and trustworthy government is broadly supported throughout society as being an attitude widely shared among citizens [24].

Transparency can be distinguished by two types: 'process transparency' or 'event transparency' [23]. In practice, most transparency through the Internet involves policy information (process) or performance results (event). This study examines the effect of direct use of process transparency by individuals. Other effects of transparency, such as transparency mediated by mass media, interest groups and trade unions, are not examined. 


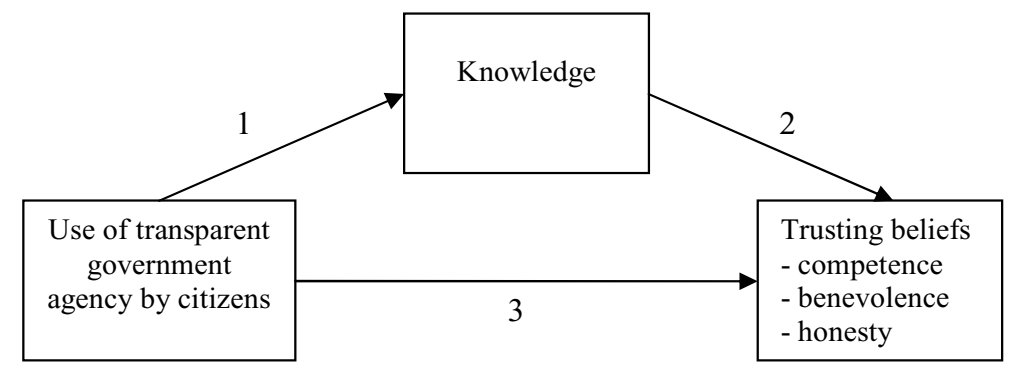

Fig. 1. Research model.

\section{Transparency and knowledge}

Knowledge about a government agency can play a mediating role in the effect of transparency on trust [37]. It is expected that transparency leads to more knowledge about the government agency, but whether more knowledge about a government agency automatically leads to more trust remains to be seen. According to Mondak et al., knowledge leads to more specific judgment criteria of citizens. For example, by having access to information about an agency's specific policy, people will judge the agency based on their knowledge of this policy, rather than basing their opinion on a general perception of the municipality or maybe even government on the national level. This experiment tested a simple partial mediation model, displayed in Figure 1.

Figure 1 shows that if people visit a government website, i.e., make use of transparency, this supposedly leads to two relationships that influence trust. First, use of transparency contributes to a person's knowledge about the government agency (arrow 1). If more information is disclosed (thus producing a higher degree of transparency), this hypothetically leads to more knowledge. Furthermore, we hypothesized that a person's knowledge could lead to altered levels of trust (arrow 2) - not that more knowledge automatically leads to more trust, but that people develop more specific judgment criteria based on their increased knowledge [37]. Analogous to this proposition, I contend that a higher degree of knowledge leads to more trust only if transparency is high. When specific judgment criteria emerges, citizens relate their perceptions more explicitly to the government agency. Since this agency is highly transparent, their judgment will become more positive and hence their trust level will become higher.

\section{Hypotheses}

There is a lack of empirical information on whether Internet transparency of government agencies influences trust, and the evidence found does not give a clear picture. That is why theoretical arguments and empirical findings are outlined using a null hypothesis (H0) and two alternative hypotheses (H1a and $\mathrm{H} 1 \mathrm{~b})$.

\section{H0: There is no effect of transparency on citizen trust in a government agency}

Van de Walle [44] studied the relationship between perceived performance of government agencies and trust in government in general. He found that there was no relationship between perceived quality of government agencies and trust in government in general. This might also apply to the setting of transparency and trust. This argument is based on the idea that the possible contribution to general trust in government (or politics) by the transparency of a particular agency is in fact negligible. For 
example, Bouckaert and Van de Walle [7, p. 334] state that "it is not even clear what influences trust in government and whether it actually has to do with the government's actions". This is supported empirically by West [46], who found no evidence for a correlation between website use and trust in government in general. Using existing survey data, Tolbert and Mossberger [43] show that visiting a federal government website does not appear to lead to more trust in federal government institutions or local governments. Although this study focuses on trust in specific government agencies instead of trust in government in general, these findings do provide some evidence for the null hypothesis.

\section{Hla: There is a positive effect of transparency on citizen trust in a government agency}

This argument is based on the idea that when citizens do not know government or what it does, they will not trust it easily. This aspect of knowledge was discussed in the previous section. It is also suggested that transparency stimulates an open culture (or at least the perception that an open culture exists), and this is supposed to have a positive effect on citizen trust [26].

The point of view that transparency will increase trust is pleaded by transparency advocates like Brin [10] and Oliver [40]. They ultimately see transparency as something good, having only a few perverse side effects. These can be eliminated through proper implementation of transparency by governments. In an outline of the debate on transparency and trust, Meijer [34] states that according to these proponents (e.g. [10,39]), lifting the veil will be beneficial to all of us and that only those who have something to hide will oppose transparency. Also, transparency offers the opportunity for government agencies to make clear to the citizens that they are not solely responsible for, for example, the quality of the air. The agency can explain to citizens how the responsibilities are divided among different public or private organizations and perhaps emphasize that citizens themselves have a responsibility in complex policy problems as well.

Welch et al. [45] found a relationship between e-government use and positive attitudes towards government. Besides, Tolbert and Mossberger [43] emphasize, based on empirical findings, that an increased perceived responsiveness of local e-government websites has a positive effect on trust. Although perceived responsiveness is not quite the same as government transparency, both concepts are related to e-government and the use of governmental websites. Therefore, this could be an indicator that Internet transparency also leads to more trust.

\section{$H 1 b$ : There is a negative effect of transparency on citizen trust in a government agency}

Opponents of transparency do not see the perverse effects of transparency as surmountable aspects. O'Neill [38, p. 77] argues that transparency will erode trust. She states that the Internet makes it possible to disclose a great deal of information, which not only leads to a flood of information but also to a flood of misinformation. This causes more uncertainty and results in confusion. Misinformation, according to O'Neill, is inseparable from transparency. Besides, officials who know that information will become public could "massage the truth". In short, we will get lost in misinformation which will produce less trust, allowing a "culture of suspicion" to arise [38, p. 77]. Other authors, like Bekkers [3] and Margetts [30], also argue that transparency could cause an information overload. Too much information elicits confusion and perhaps less appreciation from the public.

Second, by making use of increased transparency it is easier for citizens to audit government; the downside of this is that citizens might (unjustly) blame government for (small) mistakes time and time again [8]. Policy areas such as air quality are influenced by various factors: responsibility is not solely on the side of government. By making information public on a complex issue like air quality, this could give citizens the impression that this is completely the responsibility of this agency, whereas a policy area consists of complex situations and liabilities [35]. 
Table 1

Summary of experimental groups

\begin{tabular}{lccc}
\hline Group & Visit website & Measurement & $\mathrm{N}$ \\
\hline 1 (control, no transparency) & & $\mathrm{O} 1$ & 15 \\
2 (control, low transparency) & $\mathrm{X}$ & $\mathrm{O} 2$ & 14 \\
3 (experimental, high transparency) & $\mathrm{X}$ & $\mathrm{O} 3$ & 15 \\
\hline
\end{tabular}

Another result of Tolbert and Mossberger's study [43] is that improved perceptions of local government accessibility actually resulted in reduced trust in local government. Again, a concept like accessibility is not the same as transparency, but is related to it.

The debate on the effect of transparency on trust as outlined above is based mainly on theoretical arguments, and the empirical studies that are found give mixed results. Therefore, this study attempts to contribute to this debate empirically by studying the effect of transparency on citizen trust.

\section{Methodology}

The central question implies the existence of a causal effect of a condition (transparency) on trust in government agencies. To examine this, an experiment was carried out. Table 1 summarizes the information about the three groups.

There were two control groups in this experiment; one control group was assigned to fill out a questionnaire $^{1}$ without visiting a government website (i.e., not using available transparency). This controlled for a trust level in which a person did not use transparency at all. The second control group was assigned to visit a website, but was given only a small amount of information. This control group was used to find out to what extent the degree of transparency really matters for trust: so a great deal of information as opposed to there simply being little information on the website. A third group visited the actual website of the agency and was given full information.

The low-level transparency group (group 2) and the high-level transparency group (group 3) were assigned to visit the agency's website. However, the website visited by group 2 was adapted for the sake of the experiment. The adjusted website visited by the low-transparency group showed much less information than the real, high-transparency website visited by group 3. Information like the air quality plan and background information on policies, health effects, measures and links were removed. The original website of the government agency is high on transparency because it contains a great deal of information on its air quality policy, with web links to external sites which contain background

\footnotetext{
${ }^{1}$ Dimensions were operationalized in the following items, which were scored on a 5-point Likert scale. Trust is measured by calculating the means of these dimensions, the level of trust is expressed on a scale from 1 to 5 . All items were originally stated in Dutch.

Benevolence $(\alpha=684)$ :

$-[$ Agency $]$ genuinely cares about citizens.

- [Agency] does everything in its power to act in the interest of citizens.

Competence (one item):

- [Agency] is sufficiently able to perform its tasks.

Honesty $(\alpha=0.660)$ :

- [Agency] does what it promises to do.

- Civil servants of [agency] do not tell the truth (reverse).

- [Agency] performs its tasks in a sound manner.

'Knowledge' was measured by one item, asking participants to subjectively estimate their own knowledge.

- How would you, at this moment, estimate your own knowledge of [the municipality's] air quality policy?
} 
Table 2

Means of trust and knowledge

\begin{tabular}{lccccc}
\hline Transparency & Trust (average) & Benevolence & Competence & Honesty & Knowledge \\
\hline C1: No transparency & $3.43(0.09)$ & $3.43(0.19)$ & $3.53(0.18)$ & $3.31(0.14)$ & $1.53(0.22)$ \\
C2: Low-level transparency & $3.34(0.19)$ & $3.07(0.19)$ & $3.57(0.19)$ & $3.38(0.15)$ & $2.71(0.23)$ \\
High-level transparency & $3.71(0.11)$ & $3.83(0.19)$ & $3.60(0.18)$ & $3.69(0.14)$ & $3.07(0.22)$ \\
\hline
\end{tabular}

Scale $1-5$, standard errors in parentheses.

information (reports and policies) or air quality inspection reports. Another characteristic of this case of transparency is that is the real website includes positive as well as negative information about the agency. For instance, the main page says that the air quality in the municipality is below the norm, but also that it is taking measures to improve air quality. During the experiment participants in the low transparency group (group 2) did not know they were visiting a fake website, nor did they know they were given a 'set-up story'. This 'story' was a written instruction about the usability of the website. This instruction made participants visit the website in a fixed order. Participants in the group with no transparency (group 1) naturally did not get the instruction because they did not visit the website (and thus there was nothing to instruct them about). By standardizing the website visits with an instruction, it was ensured that every participant in the two 'visiting groups', read the same information. Consequently, comparability between groups 2 (low transparency) and 3 (high transparency) was increased.

To analyze a partially mediated model, it is best to estimate three linear regression models, as proposed by Baron and Kenny [2]: first, knowledge was regressed on the independent variable (transparency), which was recoded into two dummy variables. The first dummy variable was used to compare the experimental group with both control groups. The second dummy variable tested whether there were differences between the two control groups. The second step in the analysis was to regress the trust constructs on transparency. This resulted in three different regressions since three dimensions of trust were identified from the literature. Third, trust was regressed on both the independent variable (transparency) and on the mediating variable (knowledge).

All participants $(\mathrm{N}=44)$ were students living in the municipality whose website they visited; they were randomly assigned to the experimental groups. Relevant traits for trust such as ideological position, societal participation, education, age, $[17,18,41]$ political preference and the intensity of Internet use were taken into account in the analysis of the results. Because participants were assigned randomly to each group, these characteristics were distributed relatively homogeneously among the three experimental groups. Case selection was designed in such a way that participants (students living in the municipality) had some relationship with the agency in question, just as they would in a 'real' situation. Air quality in cities touches on public health; transparency on a subject like this is more likely to have an effect on trust than purely technical policy issues. This makes the selected case valid from a methodological, conceptual ('Transparency and the Internet' section) and a practical point of view, as it is impossible to visit the complete website in this experiment.

\section{Results}

Descriptive results are displayed in Table 2: mean levels of trust are displayed and standard errors are noted in parentheses. All dimensions are measured on a five-point Likert scale.

Although we cannot conclude anything statistically from Table 2, the experimental group that was 'treated' with a high degree of transparency generally showed higher means in dimensions of both trust and knowledge. Competence and honesty both produced small differences between the two control 


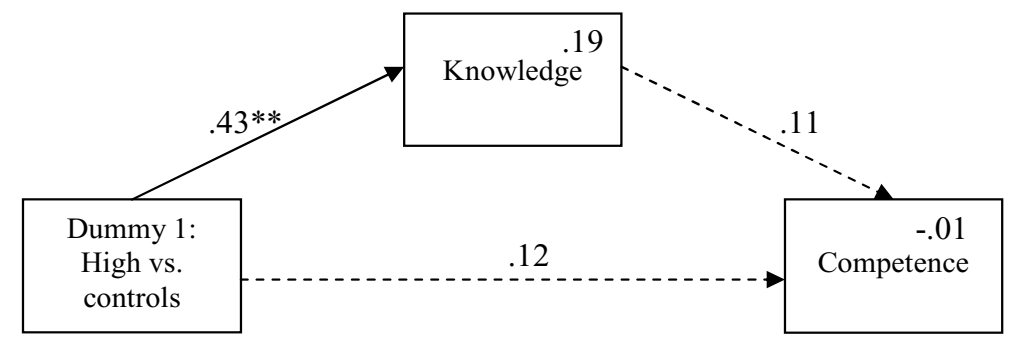

Fig. 2. Mediation model of competence (linear regression). (hence, ${ }^{*} p<0.05,{ }^{*} p<0.01$ ). Number in squares $=$ Adj. $\mathrm{R}^{2}$.

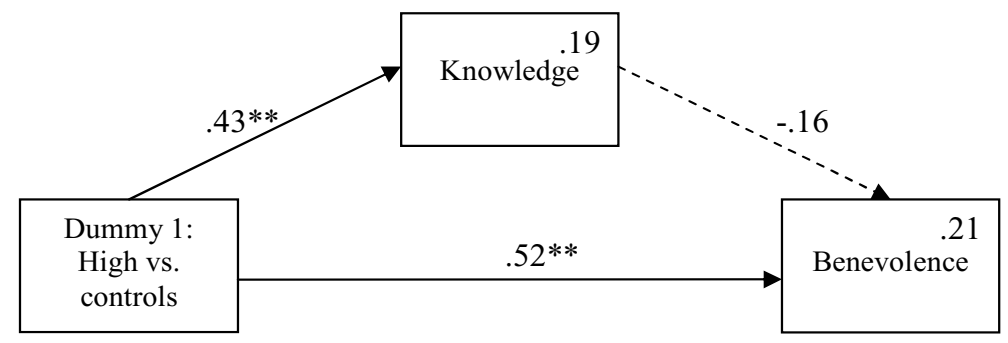

Fig. 3. Mediation model of benevolence (linear regression). (hence, ${ }^{*} p<0.05,{ }^{*} p<0.01$ ). Number in squares $=$ Adj. $\mathrm{R}^{2}$.

groups. With regard to knowledge there was a larger difference in means, which is not surprising, as one would expect people with even little information to know more about a government agency than people with no information at all. Table 2 also shows that all participants already displayed a relatively high level of trust: all scores were above three on a five-point scale. This is expected, due to the fact that the participants were all highly educated, which supposedly has a positive effect on trust.

The three-step strategy proposed in the Methodology section is presented on this page. The three regressions were repeated for all dimensions of trust. Figure 2 below shows results for participants' perceptions of the government agency's competence.

It seems that there was no significant effect of a high degree of transparency on the perception of competence in either control group. It is remarkable that providing people with more information $(\beta=$ 0.43 , significant at $p<0.01$ ) indeed increases their perception of an agency's level of knowledge, but that this does not have any effect on perceptions of competence. Nineteen percent of the variance of knowledge is explained by the degree of transparency. As can be seen from Fig. 3 (below), results of the benevolence dimension of trust demonstrate a different pattern.

In contrast to the competence dimension, Fig. 3 illustrates a highly significant $(p<0.01)$, rather strong direct effect on benevolence of $\beta=0.52$. Yet here, too, there is no mediating effect of knowledge on the dimension of trust. It even seems that it has a (non-significant) suppressing effect on benevolence. This means that there is a direct effect of a degree of transparency on benevolence compared to the control groups. This accounts for reasonable amount of variance of this dimension, namely 21 percent. Results with regard to honesty are displayed below (Fig. 4).

The pattern demonstrated in Fig. 4 is comparable yet weaker as compared to benevolence. The regression coefficient is $\beta=0.36$, which is significant at $p<0.05$. As well as in Figs 2 and 3, knowledge does not mediate transparency. Transparency only accounts for 7 percent of the variance of honesty. No significant differences were found for the second dummy variable, which estimated re gression coefficients for effects between no transparency and low transparency on the three dimensions ( Fs (1.27) 


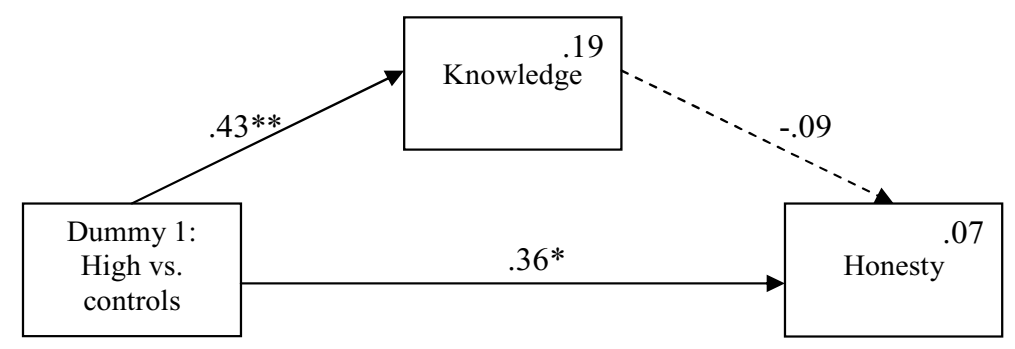

Fig. 4. Mediation model of benevolence (linear regression). (hence, ${ }^{*} p<0.05,{ }^{*} p<0.01$ ). Number in squares $=$ Adj. $\mathrm{R}^{2}$.

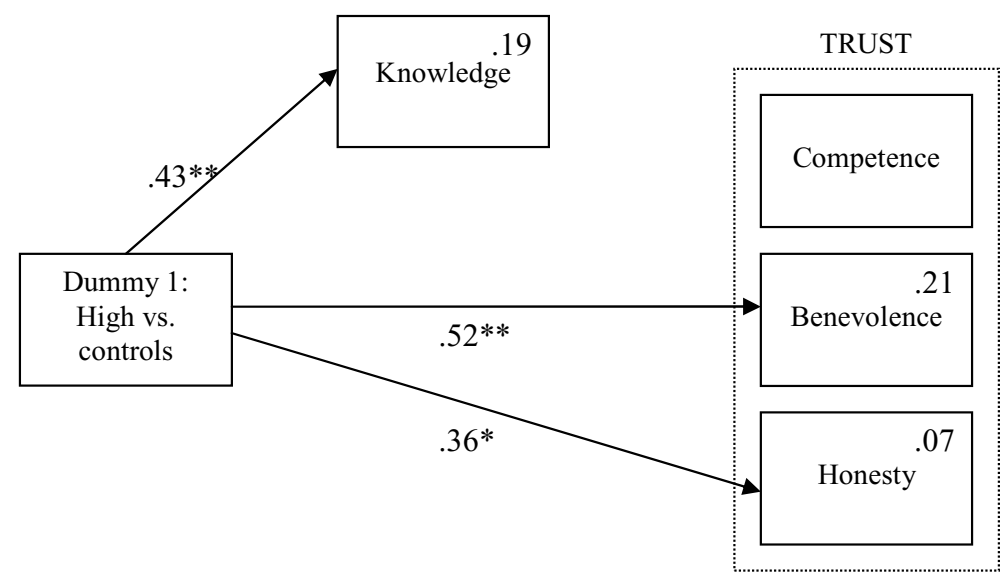

Fig. 5. Summary of the experimental model (linear regression). (hence, ${ }^{*} p<0.05,{ }^{*} p<0.01$ ). Number in squares $=$ Adj. $\mathrm{R}^{2}$.

$\leqslant 1.7, p s \geqslant 0.2)$. A low degree of transparency does have a significant effect on knowledge at the level of $p<0.01(F(1.27)=12.1)$.

In short, the analyses show differentiated results. Although the null hypothesis is rejected for two of the three studied dimensions, no mediation effect for knowledge was found. The level of information did matter for the level of knowledge participants were estimated to have. Nevertheless, knowledge even showed to have a suppressing effect on trust, though this relationship was not significant. The partial mediation model, as proposed in Section 4, should therefore be rejected. The experiment showed directed effects for two trust dimensions: honesty and benevolence. However, competence remained unaffected by the degree of transparency; this means the 'positive effect hypothesis' was only partly accepted. In summary, the following model can be made (Fig. 5).

\section{Discussion}

In contrast with Bouckaert and Van de Walle [7] this study shows that at least for government agencies, levels of citizen trust are affected by what government is and does. It appears that a high degree of transparency increases certain aspects of citizen trust in a government agency. On the other hand, although a low level of transparency does help people to gain more knowledge about the government agency, it does not increase trust as compared to giving people no information at all. Wrightsman [48] argues that basic beliefs about human nature are relied upon when little or no specific situational information is available. It might be that one refers to his or her basic belief about government in general if there is 
only a small amount of information. Apparently, this amount of information is not above the threshold that would change a person's trust beliefs.

The assertion by Mondak et al. [37] that knowledge leads to more specific judgment criteria has not been proven. On the basis of this study it is not possible to give a judgment on this. The only thing that can be said is that although knowledge increased as participants were given more information, this did not affect trust in any way. Hence, knowledge appears to play a subordinate role in the transparency-trust relationship.

This direct effect might be explained by interpreting the effects on benevolence, competence and honesty. What is striking is that the competence dimension does not differ significantly among groups, whereas benevolence and honesty do. This might be due to the fact that we examined transparency of a policy process, and not transparency of the actual performance (such as output results). Participants in the experiment have read information about policies on air quality; not about the actual performance, that is, output results about the quality of the air. Apparently, perception of competence is a distinct dimension, as this - in contrast with benevolence and honesty - refers to the concrete results of a policy. These results were not available on the website. This means transparency does not result in higher perceptions of competence because it refers to specific information about results, which cannot be deduced from this type of transparency (policy). The dimensions of honesty and benevolence do not refer to specific information or results, but to a certain moral quality of a government agency. This cannot be derived from the information directly, but only indirectly. Therefore, if people notice that there is a great deal of information online (a high level of transparency), this could be perceived as the agency making a great deal of effort in this particular policy area and hence to act in the interest of the citizen (which means a high level of perceived benevolence). The effect on perceptions of honesty - which were less dramatically affected by transparency than those of benevolence, though still significant - might be explained as follows. An agency that discloses a great deal of information about its policies - thus being highly transparent - might be perceived as an agency that probably 'has got nothing to hide'. However, this effect is less considerable as the regression coefficient of honesty is 0.36 , compared to 0.52 of benevolence. The increase in perceptions of benevolence and honesty supports Hood's [24] argument that transparency stimulates the perception that an open culture exists.

To what extent can results of this study be generalized beyond the content of this specific website of this specific government with a specific sample? First, it should be stressed that the importance of this study is closely related to the research design. In an experiment all variables except the conditional variable (transparency) are held constant. However, reality cannot be simulated completely. Participants are put behind a computer and follow a protocol, although websites or information may be read in different ways in a natural setting. For example, participants were made to watch and read the website in a particular way, while they normally might only shoot a glance at the information they are looking for. In this experiment transparency is a 'fixed state'; the use of it and the way it is used is a constant factor. This study tried to closely approximate reality, the government agency (a municipal air quality policy) being selected because participants do have some relation with air quality in their own municipality. This tension between an artificial and a real life setting expresses the weakness as well as the strength of an experiment in public administration and political science. A causal relation can be isolated from other variables, and although one might attempt to recreate a natural setting, this objective can never be achieved completely.

Second, it should be noted that the sample is not representative of the target population, as all participants were students. What does this sample bias mean for the results? Students are more highly educated; this affects knowledge and trust. The sample has a bias towards age because students are 
relatively young, which means they are more familiar with the use of the Internet. On the other hand, the effect of this bias should not be overstated. First, website use was not influenced, as it was standardized by giving participants a written instruction. Second, students appear to be actually quite representative of the target population. A survey carried out by Van Dijk et al. [16] shows that (Dutch) young people (under the age of 30) use government agencies on the Internet more than older citizens. Also, highly educated citizens use these agencies relatively more often. This means the sample bias is less than what one might initially think: the estimated goal population (users of government agency websites) is relatively young and highly educated, which are two major concerns of bias in this sample. Moreover, the main goal of this study - being an experiment - is not to achieve a perfect external validity, but to examine closely a theoretical effect by comparing relatively homogeneous groups.

A third limitation is the website that was visited. For instance, no information on the actual performance of the government agency was available online; only about their policies and policy measures. This might be the reason why perceptions of competence were not affected by transparency. This addresses another limitation of this study, namely that only one website was examined. It does not necessarily mean that results are only restricted to this website, but it probably is restricted to this type of website, i.e., type of transparency.

To summarize, there are several inherent limitations to this study because of the sample population, design and type of website that was examined. Nevertheless, it shows a differentiated set of results which give a refined view on the potential effects of Internet transparency on several dimensions of trust. People perceived the government agency to be more honest and more benevolent, yet no effects with regard to competence were detected, probably due to the type of transparency in this study.

\section{Conclusion}

This study examined the effect of transparent government agencies on trust in these agencies. First, we found that as a government agency becomes more transparent, the level of knowledge increases. However, transparency does not automatically lead to a higher level of trust in a government agency. This means that transparency of government agencies through the Internet use strengthens citizen trust in a government agency, but only if there is a high level of transparency, i.e., when much policy information with links and background information is available online.

What could these results contribute on a practical and/or theoretical level? First, transparency could prove to be a powerful instrument for policy makers in increasing citizen trust, as restoring trust is often a goal in transparency policies [43]. This study shows that if transparency is high (highly informative), it could help a government agency to increase citizen trust in this specific agency. The perception of benevolence especially can be increased by high transparency. For honesty results indicate that a high level of transparency makes citizens perceive government as being more sincere. Policymakers who want to have an influence on perceptions about government on these specific aspects of trust should give a considerable amount of information on their websites about their policies. Providing only a small amount of information about policies online, for example short propaganda-style information, is not sufficient. Only a great deal of online information, supported by policy documents, reports and links can help in achieving a higher level of (specific perceptions of) trust.

With regard to the debate on transparency, this study shows a heterogeneous effect of transparency on trust and its dimensions. A high degree of transparency considerably affects benevolence perceptions, slightly influences honesty perceptions and changes levels of trust in general as well. However, perceptions of competence stay virtually the same, which is probably not due to the small sample size. 
This could be related to the type of transparency that was object of this study (process transparency). No information on the actual performance of the government agency was available online, only about their policies and policy measures. This might be the reason why perceptions of competence were not affected by transparency. Since we controlled for both no transparency and a low degree of transparency, this study indicates that a relatively high degree of transparency really matters for trust. This study is rather small, but the results give a more detailed insight in the transparency-trust relationship. As stated in Section 5, Welch et al. [45] and Tolbert and Mossberger [43] both found a relationship between e-government use and positive attitudes towards government. Besides, Tolbert and Mossberger [43] argue, based on empirical findings, that an increased perceived responsiveness of local e-government websites has a positive effect on trust. Although perceived responsiveness is not the same as government transparency, results of this study give support to the idea that increased transparency also positively influences certain aspects of trust. Consequently, another finding by Tolbert and Mossberger, namely that increased perceived accessibility actually leads to less trust, cannot be applied to this study analogously. A cause of this might be that accessibility is a concept that is less related to transparency than perceived responsiveness. Perceived responsiveness could be influenced by changing the amount of information. Accessibility, however, remains the same, whereas access to the government website in a technical sense is guaranteed at the start of the experiment (at least for the low transparency control group). Yet further research is indeed needed to examine the effect of different types of transparency and different, larger, types of samples. Nevertheless, even this small and narrow sample showed more detailed insights in the heterogeneous effect of transparency on trust, which could add depth to the current literature.

\section{Acknowledgements}

The author would especially like to thank Mark Bovens, Albert Meijer, Martijn van der Meulen and Wieger Bakker for their valuable comments on a previous version of this paper.

\section{References}

[1] I. Ayres and J. Braithwaite, Responsive Regulation: Ranscending the Deregulation Debate, New York, Oxford University Press, 1992.

[2] R.N. Baron and D.A. Kenny, The moderator-Mediator Variable Distinction in Social Psychological Research: Conceptual, Strategic, and Statistical Considerations, in: Journal of Personality and Social Psychology 51(6) (1986), 1173-1182.

[3] V.J.J.M. Bekkers, Nieuwe Vormen van Sturing en Informatisering, Delft: Eburon, 1993.

[4] V.J.J.M. Bekkers and A. Zuurmond, Achtergronden en eigenschappen van ICT, in: ICT en Openbaar Bestuur: Implicaties en Uitdagingen van Technologische Toepassingen Voor de Overheid, M. Lips, V.J.J.M. Bekkers and A. Zuurmond, eds, Utrecht, Lemma, 2005, pp. 49-72.

[5] R. Bhattacharya, T. Devinney and M. Pillutla, A Formal Model of Trust Based on Outcomes, The Academy of Management Review 23(3) (1998), 459-472.

[6] P.J. Birkinshaw, Freedom of Information and Openness: Fundamental Human Rights, Administrative Law Review 58(1) (2006), 177-218.

[7] G. Bouckaert and S. van de Walle, Comparing measures of citizen trust and user satisfaction as indicators of 'good governance', difficulties in linking trust and satisfaction indicators, International Review of Administrative Sciences 69(3) (2003), 329-343.

[8] M.A.P. Bovens, De Digitale Republiek: Democratie en Rechtsstaat in de Informatiemaatschappij, Amsterdam, Amsterdam University Press, 2003.

[9] M.A.P. Bovens and A. Wille, Waar bleef het vertrouwen in de overheid? Bestuurskunde 15(4) (2006), 50-64.

[10] G.D. Brin, The Transparent Society: Will Privacy Force Use to Choose Between Privacy and Freedom? Reading MA: Perseus, 1998 
[11] L. Carter and F. Bélanger, The utilization of e-government service, citizen trust, innovation and acceptance factors, Information Systems Journal 15(1) (2005), 5-25.

[12] A.C. Costa, A Matter of Trust, Effects on the Performance and Effectiveness of Teams in Organizations, PhD thesis, Ridderkerk, Ridderprint, 2000.

[13] D. Curtin and A.J. Meijer, Does Transparency Strengthen Legitimacy? Information Polity 11(2) (2006), 109-123.

[14] T.H. Davenport, Process Innovation: Reengineering Work through Information Technology, Boston, Harvard School Press, 1993.

[15] P. Dekker, Individuele achtergronden van ontbrekend vertrouwen in de regering, in: Bouwen Aan Vertrouwen in Het Openbaar Bestuur: Diagnoses en Remedies, A. Korsten and P. de Goede, eds, Gravenhage, Elsevier Overheid, 2006, pp. $45-60$.

[16] J.A.G.M. Dijk, M.H.N. Hanenburg and W.J. Pieterson, Gebruik van Nederlandse Elektronische Overheidsdiensten 2006, Enschede: Twente University, 2006.

[17] M. Elchardus and W. Smits, Vertrouwen: Het vertrouwen van de Vlamingen in politiek, overheid en instellingen in tijden van affaires, in: Vlaanderen Gepeild: De Vlaamse Overheid en Waardeonderzoek, Departement Algemene Zaken en Financiën, ministerie van de Vlaamse Gemeenschap, 1998, pp. 45-91.

[18] M. Elchardus and W. Smits, Een Wantrouwig Landje, in: Vlaanderen Gepeild: De Vlaamse Overheid en Waardeonderzoek, Departement Algemene Zaken en Financiën, ministerie van de Vlaamse Gemeenschap, 2001, pp. 43-71.

[19] F. Fukuyama, Trust: The Social Virtues and the Creation of Prosperity, New York, Simon and Schuster, 1995.

[20] A.M. Fung Graham and D. Weil, Full Disclosure, Cambridge, Cambridge University Press, 2007.

[21] A. Giddens, Modernity and Self-Identity Self and Society in the Late Modern Age, Stanford: California, Stanford University Press, 1991.

[22] M. Graham, Democracy by Disclosure: The Rise of Technopopulism, Washington D.C., Brookings Institution Press, 2002.

[23] D. Heald, Varieties of Transparency, in: Transparency, The Key to Better Governance? C. Hood and D. Heald, eds, Oxford, Oxford University Press, 2006, pp. 25-43.

[24] C. Hood, Beyond Exchanging First Principles? Some Closing Comments, in: Transparency, The Key to Better Governance? C. Hood and D. Heald, eds, Oxford, Oxford University Press, 2006, pp. 211-226.

[25] R. Inglehart, Trust, well-being and democracy, in: Democracy and Trust, M.E. Warren, ed., Cambridge, Cambridge University Press, 1999, pp. 88-120.

[26] S.L. Jarvenpaa, K. Knoll and D.E. Leidner, Is anybody out there?, Antecedents of trust in global virtual teams, Journal of Management Information Systems 14(4) (1998), 29-64.

[27] S. Kim, The Role of Trust in the Modern Administrative State, An Integrative Model, Administration and Society 37(5) (2005), 611-635.

[28] A.M. Kjaer, Governance, Malden, Polity Press, 2004.

[29] M. Levi and L. Stoker, Political Trust and Trustworthiness, Annual Review of Political Science 3 (2000), 375-507.

[30] H. Margetts, Transparency and Digital Government, in: Transparency, The Key to Better Governance? C. Hood and D. Heald, eds, Oxford, Oxford University Press, 2006, pp. 197-207.

[31] R. Mayer, J.H. Davis and D. Schoorman, An Integrative Model of Organizational Trust, Academy of Management Review 20(3) (1995), 709-734.

[32] D.H. McKnight and N.L. Chervany, Reflections on an initial trust-building model, in: Handbook of Trust Research, R. Bachman and A. Zaheer, eds, Cheltenham, Edward Elgar Publishing, 2006, pp. 29-51.

[33] D.H. McKnight, V. Choudhury and C. Kacmar, Developing and Validating Trust Measures for E-commerce, An integrative Typology, Information Systems Research 13(3) (2002), 334-359.

[34] A.J. Meijer, Understanding Mediated Transparency, Using cultural sociology and media theory to understand the new transparency in the public sector, Paper Presented at the Annual EGPA Conference, Madrid, 2007.

[35] A.J. Meijer, Transparent Government, Parliamentary and legal accountability in an information age, Information Polity 8(1-2) (2003), 67-78.

[36] A.K. Mishra, Organizational Responses to Crisis, The Centrality of Trust, in: Trust in organizations, Frontiers of theory and research, R.M. Kramer and T.R. Tyler, eds, Thousand Oaks, Sage, 1996, pp. 261-287.

[37] J. Mondak, E. Carmines, R. Huckfeldt, D. Mitchell and S. Schraufnagel, Does Familiarity Breed Contempt? The impact of Information on Mass Attitudes toward Congress, American Journal of Political Science, 51(1) (2007), 34-48.

[38] O. O'Neill, A Question of Trust, The BBC Reith Lectures 2002, Cambridge, Cambridge University Press, 2002.

[39] J.S. Nye, Introduction: The Decline of Confidence in Government, in: Why People Don't Trust Government, J.S. Nye, P.D. Zelikow, D.C. King, eds, Cambridge, Harvard University Press, 1997, pp. 1-18.

[40] R.W. Oliver, What is Transparency? New York, McGraw-Hill, 2004.

[41] R. Putnam, Bowling Alone, The Collapse and Revival of American Community, New York, Simon and Schuster, 2000.

[42] A.L. Shapiro, The Control Revolution, How the Internet is Putting Individuals in Charge and Changing the World, New York, Public Affairs, 1999. 
[43] C. Tolbert and K. Mossberger, The Effects of E-government on trust and Confidence in government, Public Administration Review 66(3) (2006), 354-369.

[44] S. van de Walle, Perceptions of Administrative Performance, The Key to Trust in Government? PhD. thesis, Instituut voor de Overheid, Katholieke Universiteit Leuven, 2004.

[45] E.W. Welch, E.W. Hinnant and M.J. Moon, Linking Citizen Satisfaction with E-government and trust in government, Journal of Public Administration Research and Theory 15(3) (2005), 371-391.

[46] D.M. West, E-Government and the Transformation of Service Delivery and Citizen Attitudes, Public Administration Review 64(1) (2004), 15-27.

[47] E.M. Whitener, S.E. Brodt, M.A. Audrey and J.M. Werner, Managers as initiators of trust, an exchange relationship framework for understanding managerial trustworthy behavior, The Academy of Management Review 23(3) (1998), 513-530.

[48] L.S. Wrightsman, Interpersonal Trust and Attitudes toward Human Nature, in: Measures of Personality and Social Psychological Attitudes, J.P. Robinson, P.R. Shaver and L.S. Wrightsman, eds, San Diego, Academic Press, 1991, pp. 373-421. 